\title{
Study of the Freezing Behavior of Liposomes*
}

\author{
Masayuki KOBAYASHI**, Kenji NEMOTO**, Gaku TANAKA*** \\ and Makoto HISHIDA*** \\ **Graduate School of Science and Technology, Chiba University, \\ 1-33 Yayoi-cho, Inage-ku, Chiba-shi, Chiba, 263-8522 Japan \\ ${ }^{* * *}$ Faculty of Engineering, Chiba University, \\ 1-33 Yayoi-cho, Inage-ku, Chiba-shi, Chiba, 263-8522 Japan \\ E-mail: gtanaka@faculty.chiba-u.jp
}

\begin{abstract}
The freezing behavior of liposomes such as internal freezing, contraction by dehydration and disruption of membrane after thawing was examined by microscopic observation. Liposome suspensions were prepared by gentle hydration method using phosphatidylcholine (egg) and distilled water. The observed liposomes ranged in diameter from 5 to $150 \mu \mathrm{m}$. The sample of liposome suspensions was cooled from $-1{ }^{\circ} \mathrm{C}$ to $-50^{\circ} \mathrm{C}$ at cooling rates of 1,2 and $5{ }^{\circ} \mathrm{C} / \mathrm{min}$ and heated to $0{ }^{\circ} \mathrm{C}$ at heating rate of $10^{\circ} \mathrm{C} / \mathrm{min}$. As a result, two different patterns for freezing were observed: internal freezing and contraction without internal freezing. When the internal freezing was observed, the membrane was unexceptionally disrupted after thawing. When the internal freezing was not observed, two different cases were observed after thawing: disruptive and contractive conditions. These different freezing patterns were primarily dependent on the liposome size. In addition, the cooling rate became a key factor determining the freezing patterns in small liposomes.
\end{abstract}

Key words: Freezing, Thawing, Liposome, Freeze-Injury, Cryopreservation, Biological Engineering

\section{Introduction}

Cryopreservation techniques have the potential for preserving living cells over extended periods of time and thus have uses in a wide range of fields, including medicine, foodstuffs, animal husbandry and bioindustries. There have been a number of studies on cryopreservation, mainly in relation to the mechanisms by which cells are damaged when frozen ${ }^{(1-5)}$. These mechanisms include mechanical damage to the intracellular or membrane structure due to the formation of ice crystals within the cell as a result of rapid refrigeration, as well as chemical damage due to elevated intracellular salt concentration accompanying the dehydration contraction found with slow refrigeration. However, the freezing behavior of cells and the mechanisms by which they are damaged vary enormously with the type of cell used, and so there is great variation in post-thawing survival rate.

Liposomes, closed vesicles comprising a lipid bilayer, are widely used as cell models in the investigation of cell membrane structure and function ${ }^{(6)}$. As the cell membrane is believed to be the main part of the cell that sustains damage when the cell is frozen, liposomes are also used as models in freezing experiments ${ }^{(7-9)}$. Siminovitch et al. ${ }^{(7)}$ discovered that both liposomes and biological cells undergo dehydration contraction with slow refrigeration and internal freezing with fast refrigeration, showing major similarities. They showed that it is possible to mimic the dehydration contraction resulting from the osmotic pressure of slow refrigeration using aqueous solutions of calcium chloride and

${ }^{*}$ Received 19 Nov., 2010 (No. T2-080561) Japanese Original : Trans. Jpn. Soc. Mech. Eng., Vol. 75, No. 750, B (2009), pp.378-385 (Received 19 June, 2008) [DOI: 10.1299/jtst.6.57]

Copyright $@ 2011$ by JSME 
sodium chloride. Morris et al. ${ }^{(8)}$ investigated multilamellar liposomes and observed a relationship between freezing behavior and membrane structure and the effectiveness of cryoprotectants. Callow et al. ${ }^{(9)}$ used unilamellar liposomes the size of large cells to compare the experimental results of volumetric changes during freezing with the results of a simulation using a thermodynamic model of osmotic pressure. Nevertheless, there have been almost no systematic studies of the mechanisms of freezing damage, nor of the effects of liposome size and the rate of cooling on freezing damage.

Here, we carried out freezing experiments using liposomes as cell models. We used microscopic observation to measure and examine the freezing behavior of liposomes, such as the freezing point and dehydration contraction, and the damage after thawing. We also investigated the relationship between this behavior and liposome size and cooling rate.

\section{Apparatus and Methods}

The cell models were giant unilamellar liposomes prepared using the gentle hydration process ${ }^{(10)}$ with L- $\alpha$-phosphatidylcholine (Avanti Polar Lipids Inc.) as the phospholipid. The liquid inside and outside the liposomes was pure (distilled) water. Pure water is the simplest model, and was used because in relation to its freezing behavior in a microscopic space such as a cell, the effects of volume and cooling rate on ice nucleation and supercooling are relatively well known ${ }^{(11)}$. Figure 1 shows the results of particle size measurements using an FRA laser diffraction particle size analyzer (MicroFRA, Nikkiso Co., Ltd.). Liposomes 5-150 $\mu \mathrm{m}$ in diameter, which correspond to the size of actual cells, were selected for observation. The liposome suspension produced by the gentle hydration method contained liposomes with multilamellar construction in addition to unilamellar liposomes, and these were distinguished from one another by microscopic observation. Mulitilamellar liposomes were not included in the present study, which focused exclusively on unilamellar liposomes.

The experimental apparatus is shown schematically in Fig. 2. Observations of the freezing process were made using an optical microscope (BX 60, Olympus Corporation), with the liposome suspension on a microscope slide positioned over the interval between two copper blocks $(50 \times 60 \times 20 \mathrm{~mm})$ mounted $3 \mathrm{~mm}$ apart on the microscope stage. The blocks were cooled by circulating liquid nitrogen. Each copper block was fitted with a heater (Samicon 230, Sakaguchi E.H Voc Corp.), and the temperature was controlled using an external digital indicating controller (DB 1000, Chino Corporation) with a type K thermocouple as a proportional-integral-derivative (PID) controller. A program thermo controller (JP series, Chino Corporation) was connected to the digital indicating controller, allowing temperature programs to be set. Observations were carried out using two slides held apart by heat insulating material with dry nitrogen gas flowing over the surface of the upper slide in order to prevent condensation or frost deposition.

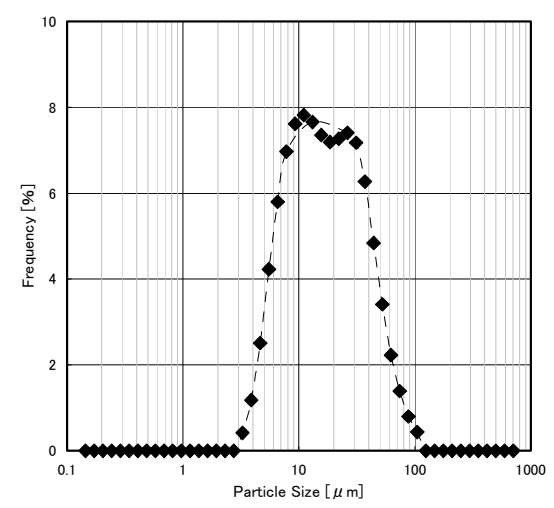

Fig. 1 Particle size distribution measured using a laser diffraction particle size analyzer. 


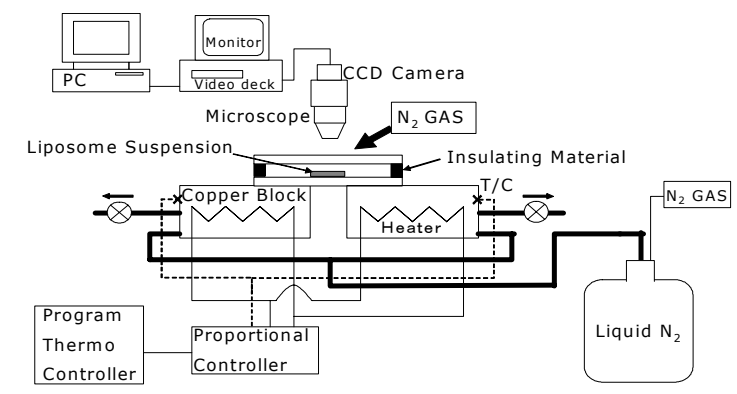

Fig. 2 Experimental apparatus.

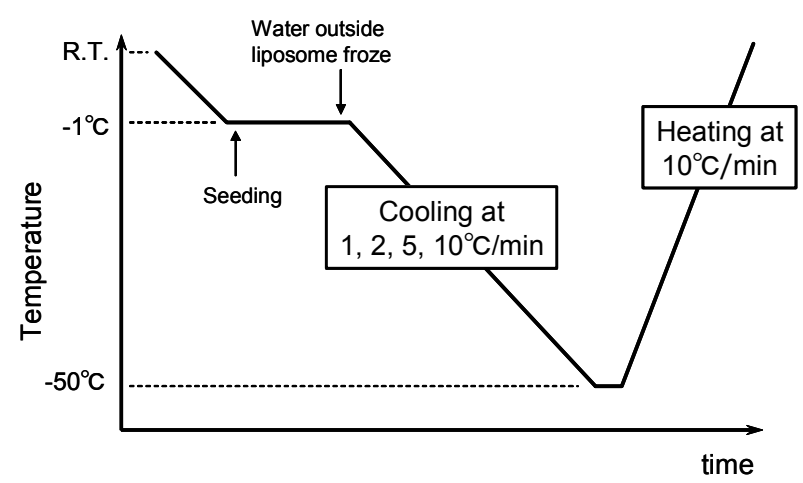

Fig. 3 Schematic diagram of experimental temperature/time protocols.

The temperature program for refrigeration and thawing is shown in Fig. 3. The freezing point of the water outside the liposomes was kept constant by carrying out ice seeding with the suspension maintained at $-1{ }^{\circ} \mathrm{C}$. Ice seeding was carried out by bringing specks of ice into contact with the liposome suspension. After freezing of the water outside the liposomes was confirmed, the suspension was cooled at a fixed rate to the final temperature of $-50{ }^{\circ} \mathrm{C}$. The cooling rates were 1,2 and $5{ }^{\circ} \mathrm{C} / \mathrm{min}$, corresponding to the cooling rates of slow cooling in the two-stage method used in cryopreservation. In addition, a cooling rate of $10^{\circ} \mathrm{C} / \mathrm{min}$ was used in a supplementary experiment that only examined the condition of liposomes after thawing. Immediately after reaching $-50^{\circ} \mathrm{C}$, the temperature was raised at a rate of 10 ${ }^{\circ} \mathrm{C} / \mathrm{min}$ and the condition of the liposomes after thawing was examined.

The temperature of the slide was measured and checked against the values of the temperature controller, showing a maximum difference of $1{ }^{\circ} \mathrm{C}$ between the temperature program and the actual temperature of the slide at 1,2 , and $5{ }^{\circ} \mathrm{C} / \mathrm{min}$. Temperature measurement by the thermocouple was found to be accurate to within $\pm 0.1{ }^{\circ} \mathrm{C}$ when tested against a standard thermometer. There was a very slight difference between the temperature of the copper block measured using the temperature controller and the temperature of the sample on the slide, with measurement of temperature distribution on the slide showing a maximum difference of $0.4^{\circ} \mathrm{C}$.

\section{Results and Discussion}

\subsection{Freezing behavior of liposomes}

3.1.1 Observation of the freezing process Three representative examples of the freezing process of liposomes are shown in Figs. 4 (a)-(c), with images taken before freezing $\left(-1{ }^{\circ} \mathrm{C}\right.$, left), freezing outside the liposome $\left(-1{ }^{\circ} \mathrm{C}\right)$, and at the final temperature $\left(-50{ }^{\circ} \mathrm{C}\right.$, right). In these three examples, the initial diameter before freezing was, respectively, 19,14 and $14 \mu \mathrm{m}$, and the cooling rate was 5,1 , and $5{ }^{\circ} \mathrm{C} / \mathrm{min}$. The 

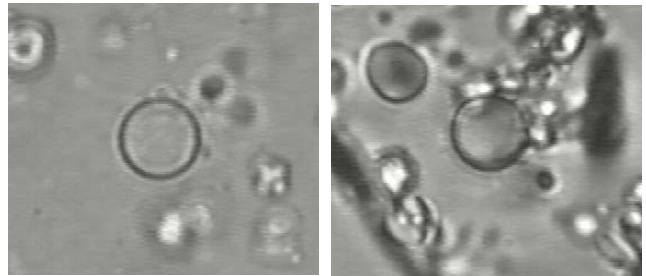

Before freezing $\left(-1^{\circ} \mathrm{C}\right)$

External freezing $\left(-1^{\circ} \mathrm{C}\right)$

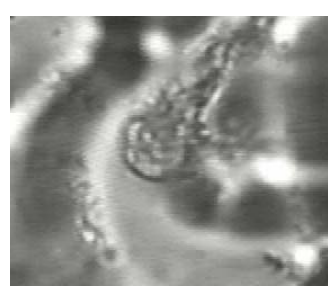

Internal freezing $\left(-9^{\circ} \mathrm{C}\right)$

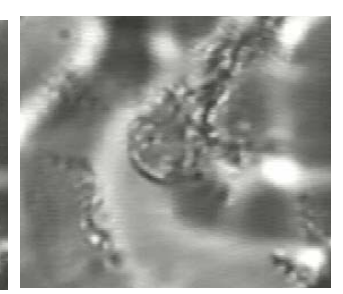

$\left(-50^{\circ} \mathrm{C}\right)$

(a) With internal freezing (Initial diameter: $19 \mu \mathrm{m}$, Cooling rate: $5{ }^{\circ} \mathrm{C} / \mathrm{min}$ )

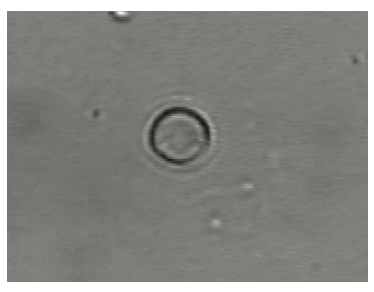

Before freezing $\left(-1{ }^{\circ} \mathrm{C}\right)$

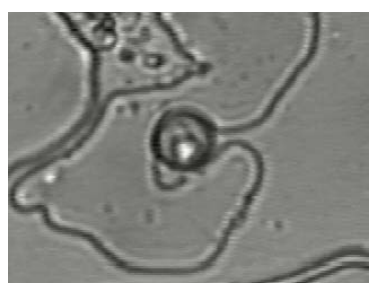

External freezing $\left(-1{ }^{\circ} \mathrm{C}\right)$

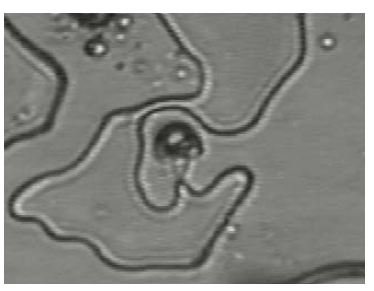

$\left(-50{ }^{\circ} \mathrm{C}\right)$

(b) Without internal freezing (Initial diameter: $14 \mu \mathrm{m}$, Cooling rate: $1{ }^{\circ} \mathrm{C} / \mathrm{min}$ )

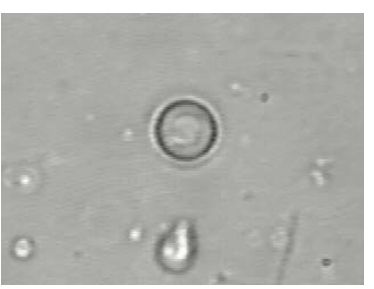

Before freezing $\left(-1{ }^{\circ} \mathrm{C}\right)$

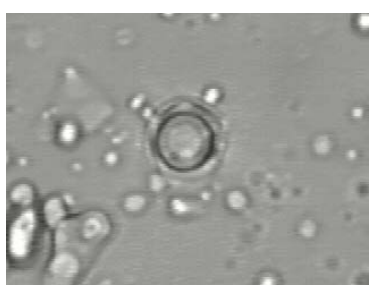

External freezing $\left(-1{ }^{\circ} \mathrm{C}\right)$

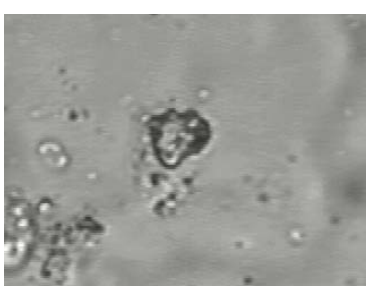

$\left(-50{ }^{\circ} \mathrm{C}\right)$

(c) Without internal freezing (Initial diameter: $14 \mu \mathrm{m}$, Cooling rate: $5{ }^{\circ} \mathrm{C} / \mathrm{min}$ )

Fig. 4 Various freezing patterns.

observations show that liposome freezing patterns may be divided broadly into patterns in which internal freezing was clearly present (Fig. 4 (a)) and those in which internal freezing was not present (Figs. 4 (b), (c)).

In Fig. 4 (a), the liposome began to change shape and contract with the lowering temperature after the outside of the liposome froze at $-1{ }^{\circ} \mathrm{C}$. Internal freezing was subsequently observed at $-9{ }^{\circ} \mathrm{C}$. Internal freezing was confirmed by momentary deformation of the liposome membrane and the "flashing" event, in which the interior of the liposome darkens. No subsequent alteration in liposome shape or volume was observed as far as the final temperature of $-50^{\circ} \mathrm{C}$.

In Figs. 4 (b) and (c), no clear internal freezing of the liposome was observed as far as $-50{ }^{\circ} \mathrm{C}$, and the liposome continued to change shape and to contract as the temperature decreased. The degree of change in liposome shape and volume at the final temperature of $-50{ }^{\circ} \mathrm{C}$ was thus larger here than when internal freezing was observed. In addition, when liposomes contracted with no internal freezing, relatively simple transformations from a sphere to an ellipsoid, as well as transformations into complex shapes due to changes such as distortion and wrinkling, were observed.

3.1.2 Internal freezing point Figures 5 (a)-(c) show the relationship between liposome internal freezing point and initial particle size at cooling rates of 1,2 , and $5{ }^{\circ} \mathrm{C} / \mathrm{min}$. The points marked on the graphs are the temperatures at which internal freezing was observed. Where no internal freezing was indicated, the position at $-50{ }^{\circ} \mathrm{C}$ is marked with an arrow $\downarrow$ on the graphs. Figures 5 (a)-(c) show that at each cooling rate, the presence of internal freezing was strongly dependent on particle size. Internal freezing was observed in relatively large liposomes of diameter greater than $20-30 \mu \mathrm{m}$, and the freezing points were 
all about $-20{ }^{\circ} \mathrm{C}$. Liposomes of smaller particle size, however, froze at lower temperatures or did not freeze at all. When comparing the different cooling rates, particularly with liposomes in the range of 20-30 $\mu \mathrm{m}$ or less in diameter, the proportion of liposomes with internal freezing increased with increased cooling rate. In addition, the particle size of the largest liposome with no internal freezing grew smaller with increased cooling rate. The largest particle with no internal freezing at $5{ }^{\circ} \mathrm{C} / \mathrm{min}$ was less than $20 \mu \mathrm{m}$.

The finding that internal freezing was not seen as particle size became smaller bears a qualitative similarity to the results of Hori ${ }^{(12)}$, who measured the freezing point of water enclosed in the gap between two glass plates (Fig. 6). Hori reported that when the gap between the glass plates was $10 \mu \mathrm{m}$ or more, the water in the gap froze at temperatures down to $-20{ }^{\circ} \mathrm{C}$, but when the gap was less than this freezing was not seen even at $-70{ }^{\circ} \mathrm{C}$ due to structuration of the water film between the plates. According to the theory of homogenous nucleation, a droplet of pure water of particle size $10 \mu \mathrm{m}$, which has a volume of the same order as the relatively small liposomes that showed no internal freezing in the present experiment, will form a single nucleus at approximately $-38{ }^{\circ} \mathrm{C}$ and will thus start to freeze. If a particle size of $1 \mu \mathrm{m}$ is assumed, the freezing point will be approximately -40 ${ }^{\circ} \mathrm{C}$. In the present experiment, internal freezing was not observed in relatively small liposomes, even at $-50{ }^{\circ} \mathrm{C}$, which is below the freezing point caused by homogenous nucleation, and thus it appears possible that the structuration of water within the liposomes affects liposome freezing behavior.

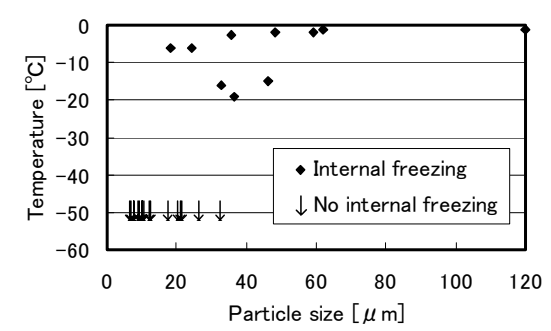

(a) Cooling rate: $1^{\circ} \mathrm{C} / \mathrm{min}$

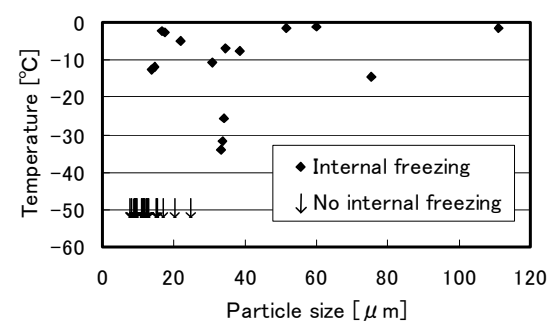

(b) Cooling rate: $2{ }^{\circ} \mathrm{C} / \mathrm{min}$

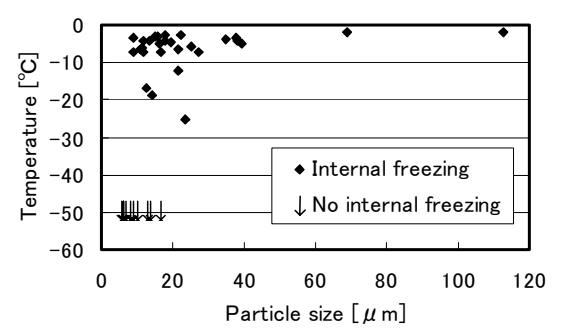

(c) Cooling rate: $5^{\circ} \mathrm{C} / \mathrm{min}$

Fig. 5 Effects of particle size on internal freezing temperature. 


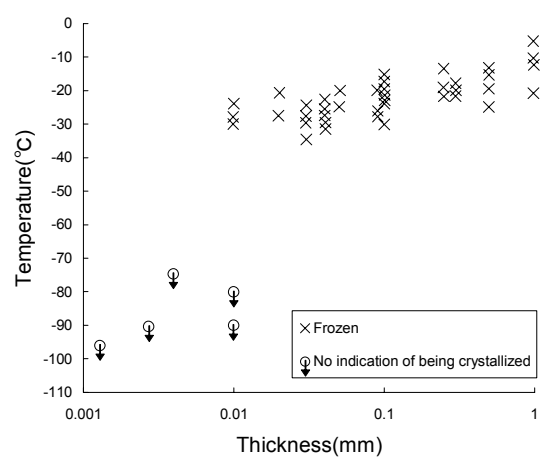

Fig. 6 Freezing temperature of water on two parallel glass plates ${ }^{(12)}$.

3.1.3 Dehydration contraction The dehydration contraction of cells has been analyzed in terms of a thermodynamic model of osmotic dehydration, using differences in chemical potential inside and outside the cell brought on by changes in the concentration of the aqueous solution outside the cell induced by freezing ${ }^{(13)}$. However, in the present experiment, the liquid both inside and outside the liposomes is pure water, and so there can be no difference between internal and external concentration as a result of freezing. We therefore examined the observed dehydration contraction using an osmotic dehydration model that only considers the difference in chemical potential between the ice outside the liposome and the supercooled water inside the liposome, which are both at the same temperature.

Using the vapor pressure of ice and of water, the difference in chemical potential between the ice and the supercooled water is given by:

$$
\frac{d \ln \left(p_{\mathrm{i}} / p_{\mathrm{W}}\right)}{d T}=\frac{H_{\mathrm{f}}}{R T^{2}}
$$

where $p_{\mathrm{i}}$ and $p_{\mathrm{w}}$ are the vapor pressure of ice and water, $T$ is the temperature, $H_{\mathrm{f}}$ is the molar heat of fusion of ice $\left(6.01 \times 10^{3} \mathrm{~J} / \mathrm{mol}\right)$, and $R$ is the gas constant $(8.31 \mathrm{~J} / \mathrm{mol} \cdot \mathrm{K})$. The drift velocity of water moving out of the liposome is given by:

$$
\frac{d V}{d t}=\frac{k S R T}{v_{0}} \ln \frac{p_{\mathrm{i}}}{p_{\mathrm{w}}}
$$

where $V$ is the volume of water inside the liposome, $t$ is the time, $k$ is the coefficient of membrane transport of water, $S$ is the surface area of the membrane, and $v_{0}$ is the molar volume of water $\left(1.8 \times 10^{-5} \mathrm{~m}^{3} / \mathrm{mol}\right)$. The temperature dependence of $k$ is given by the Arrhenius equation:

$$
k=k_{\mathrm{g}} \exp \left[-\frac{\Delta E}{R}\left(\frac{1}{T}-\frac{1}{T_{\mathrm{g}}}\right)\right]
$$

where $k_{\mathrm{g}}$ is the membrane transport coefficient at standard temperature $T_{\mathrm{g}}(272.15 \mathrm{~K})$ and $\Delta E$ is the activation energy. Furthermore, if the rate of cooling is constant $d T / d t=B$ and if the liposomes are assumed to maintain their spherical shape as they contract, from equations (1)-(3) diameter $D$ may be expressed as a function of temperature $T$ :

$$
\left[T \frac{d^{2} D}{d T^{2}}-\left(\frac{\Delta E}{R T}+1\right) \frac{d D}{d T}\right] \exp \left[\frac{\Delta E}{R}\left(\frac{1}{T}-\frac{1}{T_{\mathrm{g}}}\right)\right]=\frac{2 H_{\mathrm{f}} k_{\mathrm{g}}}{B v_{0}}
$$

At low temperatures, $k$ has almost no actual value and the exact values of $k_{\mathrm{g}}$ and $\Delta E$ are unclear. Thus, $k_{\mathrm{g}}$ and $\Delta E$ were varied and numerical solutions were calculated by the explicit method using incremental values in equation (4), and a line approximating the experimental results was obtained. The initial condition for numerical analysis was $D=D_{0}$ at $T=272.15 \mathrm{~K}$, with $d D / d T=0$ and $\Delta T=0.01 \mathrm{~K}$. 


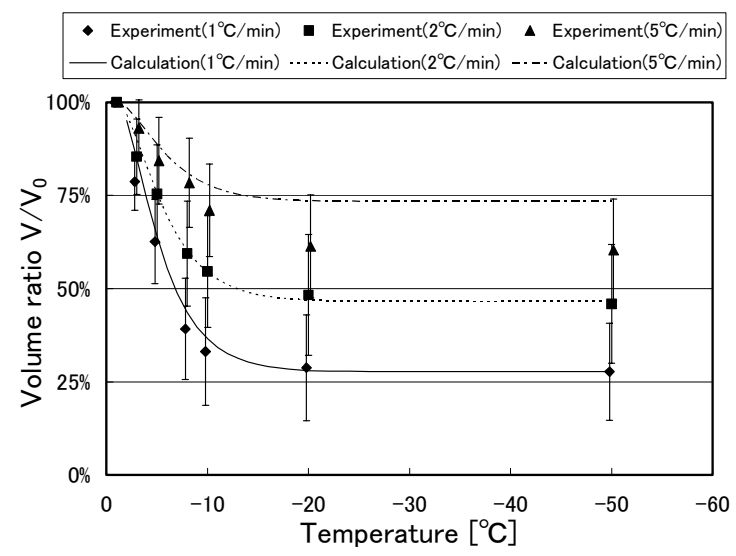

Fig. 7 Relationship between volume ratio $V / V_{0}$ and temperature.

Figure 7 shows the average volume ratio of liposomes with respect to their original volume $\left(V / V_{0}\right)$, together with the values calculated from equation (4) with $k_{\mathrm{g}}=4.0 \times 10^{-15}$ $\mathrm{m}^{3} /(\mathrm{N} \cdot \mathrm{sec})$ and $\Delta E=200 \mathrm{~kJ} / \mathrm{mol}$ for each cooling rate. The temperature dependency of the volume ratio in the experimental values shows qualitative agreement with the trend of the numerical values calculated using equation (4). Therefore, the dehydration contraction of liposomes seen in the present experiment appears to be the result of osmotic dehydration driven by the difference between $p_{\mathrm{i}}$ and $p_{\mathrm{w}}$.

The value of $k_{\mathrm{g}}$ in the present experiment was smaller by two orders of magnitude than that of egg lecithin liposomes $\left(2.91 \times 10^{-13} \mathrm{~m}^{3} /(\mathrm{N} \cdot \mathrm{s})\right)$, human leucocytes $\left(2.19 \times 10^{-13}\right.$ $\left.\mathrm{m}^{3} /(\mathrm{N} \cdot \mathrm{s})\right)$, and human erythrocytes $\left(9.41 \times 10^{-13} \mathrm{~m}^{3} /(\mathrm{N} \cdot \mathrm{s})\right)$ measured at around room temperature, and was of the same order as cells such as Amoeba proteus $\left(4.31 \times 10^{-15} \mathrm{~m}^{3} /(\mathrm{N}\right.$. s)) or onion epithelium $\left(9.95 \times 10^{-15} \mathrm{~m}^{3} /(\mathrm{N} \cdot \mathrm{sec})\right)^{(9,14)}$. In addition, the value of $\Delta E$ in the experiment was of an order of magnitude larger than human erythrocytes (approx. 20 $\mathrm{kJ} / \mathrm{mol})$, mouse eggs $(58.6 \mathrm{~kJ} / \mathrm{mol})$, and onion epithelium $(44.7 \mathrm{~kJ} / \mathrm{mol})^{(13-15)}$. The reason for the discrepancy with the values cited in the literature is that the values in the literature were measured at a temperature range mainly around room temperature. It has been shown experimentally using human endothelial cells that $k_{\mathrm{g}}$ decreases sharply and $\Delta E$ increases in measurements made in a low temperature environment ${ }^{(16)}$, and this is likely the reason for the comparatively low $k_{\mathrm{g}}$ and high $\Delta E$ observed in the present experiment.

\subsection{Damage after freezing/thawing}

3.2.1 Observation after thawing Figure 8 shows three representative examples of images of liposomes after thawing. The left-hand images are before thawing $\left(-50^{\circ} \mathrm{C}\right)$, the right-hand images are after thawing $\left(0^{\circ} \mathrm{C}\right)$, and the liposomes in (a)-(c) are the same as those for which the cooling process is shown in Figs. 4 (a)-(c). In all cases where there was internal freezing, as in Fig. 8 (a), without exception the membrane was disrupted into small fragments and dispersed. Where internal freezing was not seen, as in Figs. 8 (b) and (c), there were cases where the membrane was similarly disrupted into small fragments, there were cases such as in Fig. 8 (b), where the original liposome split into smaller liposomes, and there were cases such as in Fig. 8 (c), where the liposome recovered approximately the same spherical shape as before cooling. However, even when the liposomes recovered their spherical shape, the size was almost never the same as the initial (pre-cooling) size, and the liposomes contracted to an average of approximately $80 \%$ of their pre-cooling diameter. This appears to be because dehydration contraction occurred during cooling due to the differing states of the supercooled water inside the liposome and the ice outside, whereas during thawing a chemical potential in the reverse direction did not occur and there was thus no movement of water. 


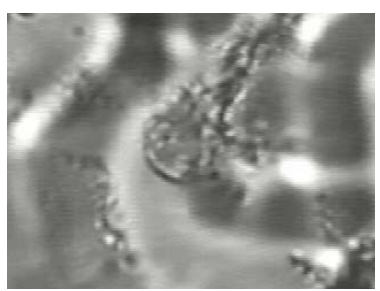

$\left(-50{ }^{\circ} \mathrm{C}\right)$

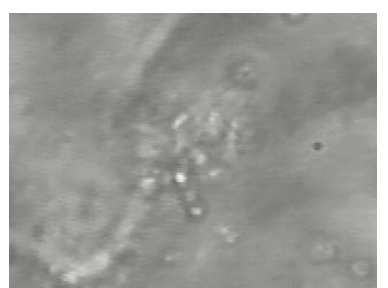

After thawing $\left(0^{\circ} \mathrm{C}\right)$

(a)Disruption with internal freezing (Initial diameter: $19 \mu \mathrm{m}$, Thawing rate: $10^{\circ} \mathrm{C} / \mathrm{min}$ )

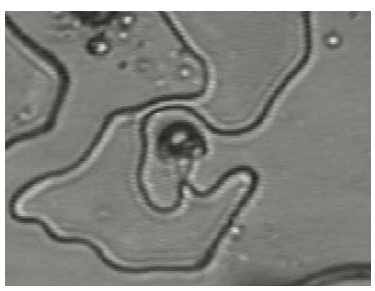

$\left(-50^{\circ} \mathrm{C}\right)$

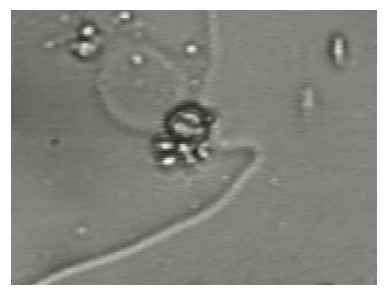

After thawing $\left(0^{\circ} \mathrm{C}\right)$

(b) Fission without internal freezing

(Initial diameter: $14 \mu \mathrm{m}$, Thawing rate: $10^{\circ} \mathrm{C} / \mathrm{min}$ )

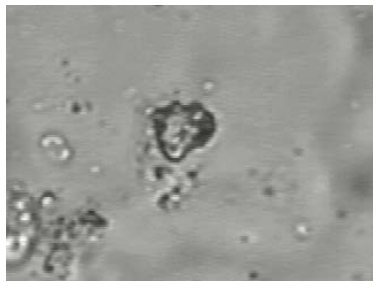

$\left(-50^{\circ} \mathrm{C}\right)$

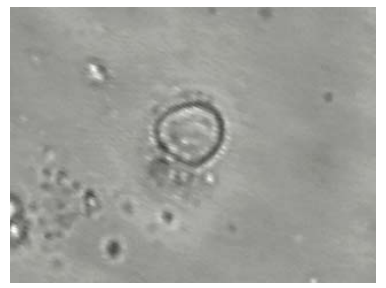

After thawing $\left(0^{\circ} \mathrm{C}\right)$

(c) Recovery without internal freezing (Initial diameter: $14 \mu \mathrm{m}$, Thawing rate: $10^{\circ} \mathrm{C} / \mathrm{min}$ )

Fig. 8 Thawing behavior of liposomes.

Looking at this from the point of view of cryopreservation of cells, where the liposomes are disrupted into small fragments or split into several smaller liposomes, as in Figs. 8 (a) and (b), there is likely to be lethal damage to membrane function. Where the liposomes are restored to more or less spherical shape as in Fig. 8 (c), however, it is likely that no lethal damage is sustained.

3.2.2 Effect of particle size and cooling rate on damage Observation after freezing and thawing showed that liposome damage can be broadly divided into three patterns: (I) internal freezing observed during cooling, membrane disrupted into small fragments after thawing; (II) internal freezing not observed, liposome disrupted or split; and (III) internal freezing not observed, liposomes restored to spherical shape (deviation from roundness [minor axis/major axis ratio of distorted liposomes] is $\geq 0.8$ ). Figures 9 (a)-(c) show the relationship between the proportion in which each pattern was found and the cooling rate for particle sizes of (a) 5-20 $\mu \mathrm{m}$, (b) $20-40 \mu \mathrm{m}$, and (c) $>40 \mu \mathrm{m}$. The figures in the diagrams indicate the number of times each experiment was performed. Patterns (I)-(III) are all seen in Fig. 9 (a), whereas only (I) and (II) are seen in 9 (b) and only (I) is seen in 9 (c). Thus, the proportion with which each pattern appears varies with particle size, and with small particle sizes in particular the proportion depends strongly on the cooling rate.

In Fig. 9 (a), pattern (I) scarcely appears and pattern (II) accounts for approximately $70 \%$ of the total at $1{ }^{\circ} \mathrm{C} / \mathrm{min}$. However, the proportion of (I) increased and the proportion of (II) decreased as the cooling rate increased, so the situation is reversed and (I) accounts for approximately $60 \%$ of the total at $5{ }^{\circ} \mathrm{C} / \mathrm{min}$. The proportion of pattern (III) at all cooling 


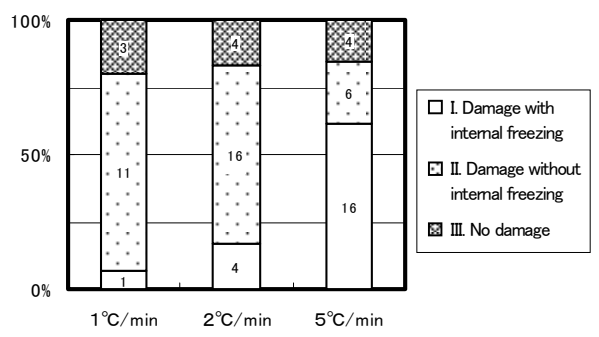

(a) Particle size: $5-20 \mu \mathrm{m}$

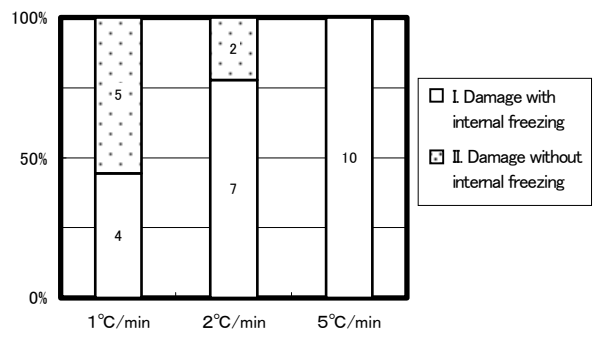

(b) Particle size: $20-40 \mu \mathrm{m}$

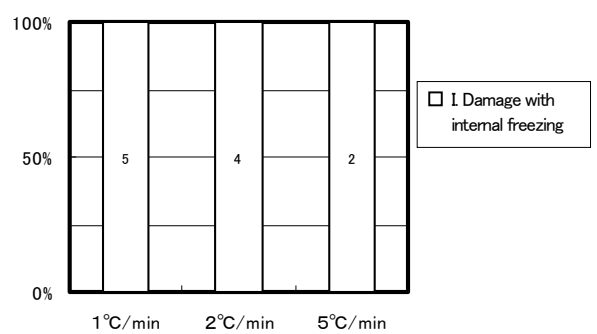

(c) Particle size: $>40 \mu \mathrm{m}$

Fig. 9 Effects of cooling rate on the percentage of three damage patterns after thawing.

rates was relatively low, at $15-20 \%$. In Fig. 9 (b), the proportion of pattern (I) increased and the proportion of pattern (II) decreased as the cooling rate increased, just as in 9 (a), and at $5{ }^{\circ} \mathrm{C} / \mathrm{min}$ the proportion of pattern (I) reached $100 \%$. In Fig. 9 (c), the results were all pattern (I) regardless of cooling rate, and thus the membrane of all liposomes was disrupted into small fragments as a result of internal freezing when the particle size was large.

The results shown in Fig. 9 indicate that even when internal freezing is not observed, many of the liposomes do not recover their pre-freezing spherical shape after thawing due to damage such as splitting or marked deformation. The damage is probably caused by the mechanical action of ice crystals outside the liposome on the membrane during cooling ${ }^{(1)}$, or mechanical damage to the membrane due to excessive volumetric changes ${ }^{(17)}$. In addition, while some of the liposomes in which no internal freezing was found recovered their spherical shape without sustaining damage, as noted in the preceding section, they did not return to their original size. This is likely because the liquid inside and outside the liposomes in the present experiment was pure water. If an aqueous solution were used, there would likely be dehydration contraction during freezing due to the difference in concentration inside and outside the liposome caused by freezing, and the liposome would then swell again during thawing. In the present experiment, there was dehydration contraction during freezing because of the different conditions of super-cooled water inside the liposomes and ice outside, whereas during thawing the conditions inside and outside the liposomes were the same, so that the liposomes did not swell again.

\subsection{Relation to cryopreservation of living cells}

Pattern (III), in which liposomes in the relatively small particle size range recovered their spherical shape after thawing without disruption or splitting, was seen in the present experiment. We therefore showed the relationship between the proportion of liposomes in 
the size range 5-20 $\mu \mathrm{m}$ recovering their spherical shape and the cooling rate, and also the relationship between the rate of volumetric change of liposomes recovering their spherical shape and the cooling rate, in order to investigate the relevance of the experimental results to knowledge obtained from the cryopreservation of living cells.

Figure 10 shows the relationship between the proportion of $5-$ to $20-\mu \mathrm{m}$ particles recovering their original spherical shape (no damage rate) and cooling rate. This figure includes the results used up to Fig. 9, with the addition of the results of an experiment with a cooling rate of $10{ }^{\circ} \mathrm{C} / \mathrm{min}$ carried out specifically for this investigation. At a cooling rate of $10^{\circ} \mathrm{C} / \mathrm{min}$, in all cases $(\mathrm{n}=10)$, internal freezing was observed and the membrane was disrupted into small fragments after thawing, corresponding to pattern (I). As in Fig. 9 (a), the recovery rate was determined by the increased rate of damage due to internal freezing and the decreased rate of damage other than internal freezing as the cooling rate increased. It was also found that as the cooling rate increased, all the liposomes were eventually damaged by internal freezing.

Figure 11 shows the relationship between the rate of volumetric change (contraction rate) of liposomes that recovered their spherical shape and cooling rate. The average contraction rates at 1,2 and $5{ }^{\circ} \mathrm{C}$ were, respectively, $0.37,0.64$, and 0.74 . The differences in contraction rate are due to the big differences in the amount of dehydration contraction at different cooling rates. The minimum critical volume hypothesis maintains that below a critical cell volume, damage to living cells during slow cooling is due to cell contraction. According to this hypothesis, cells such as human erythrocytes will have a contraction rate in the order of 0.35 and will begin to sustain irreversible damage ${ }^{(18)}$. It is therefore possible that even liposomes that recovered their spherical shape in the present experiment may

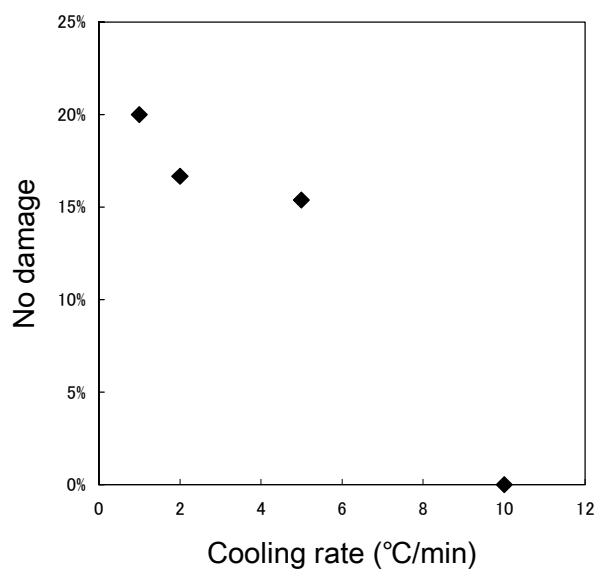

Fig. 10 Relationship between no damage rate and cooling rate (Particle size: 5-20 $\mu \mathrm{m}$ ).

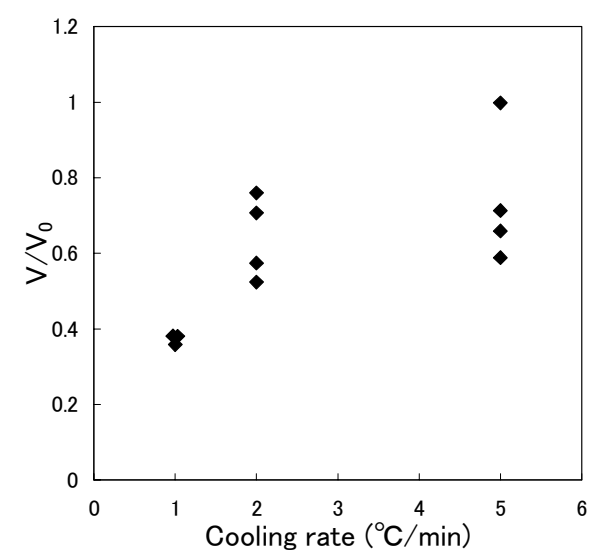

Fig. 11 Relationship between contraction rate and cooling rate (Particle size: 5-20 $\mu \mathrm{m}$ ). 
sustain damage at a low cooling rate as a result of drastic reduction in volume caused by dehydration contraction.

In the cryopreservation of living cells, optimal cooling rates at which high rates of survival after thawing can be obtained have been reported for various different types of cell ${ }^{(19)}$. In the liposomes of small particle size used in the present experiment, the rate of damage due to internal freezing increased with increased cooling rate, while at lower cooling rates, the rate of damage other than by internal freezing increased and marked reduction in volume was seen. This suggests the existence of a range of cooling rates within which freezing damage does not readily occur. Survival rates and optimal cooling rates vary according to the type of cell used for cryopreservation, making quantitative comparisons difficult. Nonetheless, the extremely simple series of liposomes used in the present study exhibits the basic characteristics of internal freezing and dehydration contraction that impact the survival rate of cells.

The liquid inside and outside the liposomes in the present study was pure water, whereas intra- and extracellular fluids are aqueous solutions. Aqueous solutions exhibit different freezing behavior than pure water due to effects such as the formation of concentration gradients within the solution ${ }^{(20)}$. If aqueous solution were used for the internal and external liquid of the liposomes instead of pure water, there would be differences in dehydration contraction and subsequent swelling as a result of differences in freezing point and ice crystal shape, as well as differences in concentration between the inside and the outside of the liposome. Because these characteristics are factors that directly affect damage to the liposome, it would be problematic to simply apply the quantitative relationships between liposome damage and liposome size or cooling rate obtained using pure water in the present study to aqueous solutions.

\section{Conclusion}

The freezing and thawing process of liposomes of particle size $5-150 \mu \mathrm{m}$ from $-1{ }^{\circ} \mathrm{C}$ to $-50{ }^{\circ} \mathrm{C}$ was investigated at cooling rates of $1,2,5$ and $10{ }^{\circ} \mathrm{C} / \mathrm{min}$, and a warming rate of 10 ${ }^{\circ} \mathrm{C} / \mathrm{min}$. The findings are as follows:

1. Freezing behavior depended mainly on particle size, and two patterns for freezing were observed: internal freezing and deformation/contraction without internal freezing. The latter pattern was only observed with small liposomes of particle size 20-30 $\mu \mathrm{m}$ or less.

2. The freezing behavior of small liposomes less than 20-30 $\mu \mathrm{m}$ depended on the cooling rate. As the cooling rate increased, the proportion of liposomes with internal freezing increased and the maximum size of liposomes with no internal freezing became smaller.

3. Without exception, all liposomes in which internal freezing was observed were disrupted into small fragments after thawing. When there was no internal freezing, some liposomes were disrupted or split, and a small number returned almost fully to their original spherical shape.

4. In small liposomes of particle size 5-20 $\mu \mathrm{m}$, an increase in the proportion of liposomes damaged by internal freezing was observed with increased cooling rate, and an increase in the proportion damaged by causes other than internal freezing, as well as a marked decrease in volume, was observed with decreased cooling rate.

\section{Acknowledgement}

We would like to express our deep gratitude to Dr. Kunikazu Moribe, associate professor at Chiba University Graduate School of Pharmaceutical Sciences, for his help and advice in carrying out this study. 


\section{References}

(1) Ishiguro, H. and Rubinsky, B., Microscopic behavior of ice crystals and biological cells during directional solidification of solutions with cells, Transactions of the Japan Society of Mechanical Engineers, Series B, Vol. 60, No. 572 (1994), pp. 1349-1355.

(2) Shirakashi, R. and Tanasawa, I., Measurement of critical osmotic pressure for biological cells (Minimum cell-volume-ratio as an estimation of viability), Transactions of the Japan Society of Mechanical Engineers, Series B, Vol. 64, No. 623 (1998), pp. 2362-2366.

(3) Tsuruta, T., Kawamizu, T., Nonaka, I. and Masuoka, T., Experimental study on freezing of onion skin cells (Intracellular ice formation and dehydration with extracellular solution), Transactions of the Japan Society of Mechanical Engineers, Series B, Vol. 62, No. 598 (1996), pp. 2446-2451.

(4) Tada, Y. et al., Micro-behavior and viability of biological cell during freezing, Transactions of the Japan Society of Mechanical Engineers, Series B, Vol. 71, No. 702 (2005), pp. 602-609.

(5) Takamatsu, H., Zawlodzka, S. and Miyanaga, T., Effect of extracellular ice formation and electrolyte concentration on injury of slowly frozen cells, Transactions of the Japan Society of Mechanical Engineers, Series B, Vol. 72, No. 717 (2006), pp. 1342-1348.

(6) Shirakashi, R. and Taniguchi, K., Mechanism of electroformation based on the analysis of the giant-unilamelar-vesicle (GUV) dynamics during production, Transactions of the Japan Society of Mechanical Engineers, Series B, Vol. 73, No. 725 (2007), pp. 387-393.

(7) Siminovitch, D. and Chapman, D., Liposome bilayer model systems of freezing living cells, FEBS LETTERS, Vol. 16, No. 3 (1971), pp. 207-212.

(8) Morris, G. J. and McGrath, J. J., The response of multilamellar liposomes to freezing and thawing, Cryobiology, Vol. 18 (1981), pp. 390-398.

(9) Callow, R. A. and McGrath, J. J., Thermodynamic modeling and cryomicroscopy of cell-size, unilamellar, and paucilamellar liposomes, Cryobiology, Vol. 22 (1985), pp. 251-267.

(10) Oku, N., Liposomes: preparation and experimentation (in Japanese), (1994), Hirokawa Publishing Co.

(11) Fukusako, S. and Inaba, H., Heat transfer phenomena and its application under low temperature environment (in Japanese), (1996), Yokendo Ltd.

(12) Hori, T., On the supercooling and evaporation of thin water films. I., Low Temperature Science, Ser. A, 15 (1956), pp. 33-42.

(13) Mazur, P., Rall, W. F. and Leibo, S. P., Kinetics of water loss and the likelihood of intracellular freezing in mouse ova, Cell Biophysics, Vol. 6 (1984), pp. 197-213.

(14) Tsuruta, T., Ishimoto, Y. and Masuoka, T., Intracellular ice formation and dehydration of onion epidermis, 35th National Heat Transfer Symposium of Japan, Vol. III (1998), pp. 833-834.

(15) McGrath, J.J., Diller, K.R., Ed., Low temperature biotechnology, ASME BED-Vol. 10, HTD-Vol. 98 (1988), pp. 273-330.

(16) Shirakashi, R. and Tanasawa, I., Measurement of membrane permeability of a biological cell, Transactions of the Japan Society of Mechanical Engineers, Series B, Vol. 64, No. 622 (1998), pp. 1867-1871.

(17) Takamatsu, H., Kawahara, S., Kurosawa, T. and Honda, H., Osmotic volume change and cellular injury by hypertonic sodium choloride solution, Transactions of the Japan Society of Mechanical Engineers, Series B, Vol. 68, No. 672 (2002), pp. 2320-2326.

(18) Meryman, H. T., Freezing injury and its prevention in living cells, Annual Review of Biophysics and Bioengineering, Vol. 3 (1974), pp. 341-363.

(19) Sakai, A., Cryopreservation (in Japanese), (1987), Asakura Publishing Co.

(20) Franks, F., Biophysics and biochemistry at low temperatures, (1985), Cambridge University Press 